\title{
Causes of the Global Warming Observed since the 19th Century
}

\author{
Michael J. Ring, Daniela Lindner, Emily F. Cross, Michael E. Schlesinger \\ Climate Research Group, Department of Atmospheric Sciences, University of Illinois at Urbana-Champaign, Urbana, USA \\ Email: mjring@atmos.uiuc.edu
}

Received May 7, 2012; revised June 10, 2012; accepted June 21, 2012

\begin{abstract}
Measurements show that the Earth's global-average near-surface temperature has increased by about $0.8^{\circ} \mathrm{C}$ since the 19th century. It is critically important to determine whether this global warming is due to natural causes, as contended by climate contrarians, or by human activities, as argued by the Intergovernmental Panel on Climate Change. This study updates our earlier calculations which showed that the observed global warming was predominantly human-caused. Two independent methods are used to analyze the temperature measurements: Singular Spectrum Analysis and Climate Model Simulation. The concurrence of the results of the two methods, each using 13 additional years of temperature measurements from 1998 through 2010, shows that it is humanity, not nature, that has increased the Earth's global temperature since the 19th century. Humanity is also responsible for the most recent period of warming from 1976 to 2010. Internal climate variability is primarily responsible for the early 20th century warming from 1904 to 1944 and the subsequent cooling from 1944 to 1976. It is also found that the equilibrium climate sensitivity is on the low side of the range given in the IPCC Fourth Assessment Report.
\end{abstract}

Keywords: Climate Change; Global Warming; Climate Forcing; Internal Variability

\section{Introduction}

It is well known that the global, instrumental near-surface temperature records show a warming of Earth's surface since the 19th century. It is equally certain that the concentrations of greenhouse gases have risen in Earth's atmosphere due to humanity's consumption of fossil fuels. However, to conclude the rise of global temperature is caused by the recent increase in greenhouse gases is more difficult, since the greenhouse gases are not the only factors affecting Earth's climate. External but natural factors such as volcanoes and changes in solar irradiance also alter global temperatures. Additionally, Earth's climate system contains a wealth of natural, internal variability. Among these manifestations are oscillations with a somewhat regular period such as the El NiñoSouthern Oscillation and the Atlantic Multidecadal Oscillation [1], as well as stochastic climate noise.

Over the course of its four Assessment Reports, the Intergovernmental Panel on Climate Change (IPCC) has become increasingly certain of the role that humans have played in contributing to the observed warming. The IPCC's First Assessment Report in 1990 noted that the observed global-mean near-surface temperature in the previous 100 years "is broadly consistent with predicttions of climate models, but it is also of the same magnitude as natural climate variability. Thus the observed increase could be largely due to this natural variability, alternatively this variability and other human factors could have offset a still larger human-induced greenhouse warming" [2]. But in the most recent Fourth Assessment Report in 2007, the IPCC stated that "most of the observed increase in global average temperatures since the mid-20th century is very likely due to the observed increase in anthropogenic greenhouse gas concentrations" [3]. While this conclusion is not completely universal in the scientific community [4], the remaining level of scientific skepticism regarding Earth's warming, and humanity's contribution toward these changes, is small.

In contrast, the level of skepticism regarding global warming among the general public, at least in the United States, remains much higher. In the annual Gallup environment poll, the percentage of Americans who cited "pollution from human activities" as the major cause of the observed temperature increase was 50 percent in 2010 and 52 percent in 2011, while the percentage of those citing "natural changes in the environment" as the major cause was 46 percent in 2010 and 43 percent in 2011. But, as recently as 2008 the percentage of the public responding "pollution from human activities" was twenty percentage points higher than those choosing "natural changes in the environment". Yet the number of 
Americans who say they understand the issue "very well" or "fairly well" has increased from 69 percent in 2001 to 80 percent in the 2011 survey [5]. While the recognition of humanity's role in climate change has become stronger within the scientific community in the past decade, the opposite has happened among the American public. In turn, the weak public acceptance of humanity's role in climate change has made policy choices in favor of emissions reductions a political impossibility so far.

While some of the skeptical members of the general public may never be willing to consider scientific evidence regarding the human role in climate change, we believe there are others who are willing to consider such evidence. However, for this to happen, the evidence presented to members of the general public must be accessible and understandable. While there have been a number of important advances in detection and attribution of climate change since the foundation of the IPCC, with particular attention focused on the "optimal fingerprinting" multivariate regression technique (see reviews by [6] and [7] for further details), the methods used in those studies have become increasingly complex and bewildering to members of the general public, and even to other scientists. We believe there is a role for simple, effective, accessible studies of the causes of global climate change, and that the results of these studies are especially important for communication to the general public. We therefore choose a simpler approach here, returning to previous work by our Group [8]. Our goal is to make the results of our research accessible and understandable to non-scientists, as well as to scientists. We believe communication of the results of this study is important to redress the skepticism regarding anthropogenic global warming outside the scientific community.

We use our Climate Research Group's Simple Climate Model (SCM) [9] to determine the causes of the observed temperature increases in four near-surface instrumental temperature records: HADCRUT4, the record compiled by the Hadley Centre and the University of East Anglia [10]; GISTEMP, the record compiled by the National Aeronautic and Space Administration's Goddard Institute for Space Studies [11]; the National Oceanographic and Atmospheric Administration's (NOAA) National Climatic Data Center (NCDC) record [12]; and the Japanese Meteorological Agency (JMA) record $[13,14]$. In so doing we will update and extend the previous study [8] which showed that anthropogenic forcings were the primary cause of the observed warming since pre-industrialization, and a co-equal cause with natural variability of the warming in the 1976-1990 period.

We also use Singular Spectrum Analysis (SSA), a type of Fourier spectral analysis with data-determined structures (basis functions) in time to determine both the trend and natural variability in the observed temperatures. This analysis does not use the SCM in any way.

Additional details regarding the SCM and SSA may be found in Section 2. Our results are presented in Section 3. In Section 4 we offer discussion of our findings. We summarize in Section 5.

\section{Methods}

In this study we determine and compare the temperature trend found through two separate techniques: simulations using our SCM, and Singular Spectrum Analysis (SSA) of the instrumental temperature records. We use our SCM to determine the amount of temperature change caused by each of the external radiative forcings - the change in the net incoming radiation at the top of Earth's atmosphere. We use SSA to determine the amount of temperature change caused by the internal variability. Below we describe each method in more detail.

\subsection{Summary of Simple Climate Model}

We use our SCM [9] to produce simulations of the historical global-mean temperature change by minimizing the root-mean-square differences between observed and simulated quantities. In this section, we summarize the SCM procedure. Readers interested in more details may read the next subsection.

Three SCM parameters are estimated based on comparisons to the observed data. The equilibrium climate sensitivity, $\Delta \mathrm{T}_{2 \mathrm{x}}$ - the change in global-mean, equilibrium near-surface temperature for a radiative forcing equivalent to a doubling of the pre-industrial $\mathrm{CO}_{2}$ concentration - is estimated using the observed global-mean near-surface temperature. The aerosol radiative forcing in reference year $2000, \mathrm{~F}_{\mathrm{A}}(2000)$, is estimated using the observed interhemispheric near-surface temperature difference. The ocean thermal diffusivity, $\kappa$, is estimated using the observed upper ocean heat uptake. For the temperature comparisons, we consider the four different instrumental temperature records mentioned in Section 1. The simulated upper ocean heat uptake is compared to [15].

The SCM considers both natural and anthropogenic external forcings. A summary of the global-mean magnitudes of each forcing source between 1850 and present day is found in Table 1; note that some of the radiative forcings have different magnitudes in the Northern and Southern Hemispheres.

We perform simulations using all the external forcings, and simulations using only the natural, external forcings. This allows us to assess whether the natural forcings alone are sufficient to reproduce the observed temperature increase, or the trend found through SSA analysis (see Section 2.3). 
Table 1. Summary of magnitudes for individual radiative forcing sources.

\begin{tabular}{|c|c|}
\hline Source & $\begin{array}{l}\text { Change in global-mean radiative } \\
\text { forcing, } 1850 \text { to present }\end{array}$ \\
\hline Long-lived greenhouse gases & $2.62 \mathrm{Wm}^{-2}$ \\
\hline $\begin{array}{l}\text { Aerosols (Sum of sulfate, black } \\
\text { carbon, and organic carbon) }\end{array}$ & $\begin{array}{c}\mathrm{k}-0.99 \mathrm{Wm}^{-2} \text { to }-0.42 \mathrm{Wm}^{-2} \text {, depend- } \\
\text { ing on dataset }\end{array}$ \\
\hline Tropospheric ozone & $0.39 \mathrm{Wm}^{-2}$ \\
\hline Changes in land use & $-0.16 \mathrm{Wm}^{-2}$ \\
\hline Changes in solar irradiance & $\begin{array}{c}\text { About } 0.1 \mathrm{Wm}^{-2} \text { secular increase; } \\
\text { 11-year cycle contributes an additional } \\
\pm 0.1 \mathrm{Wm}^{-2}\end{array}$ \\
\hline Volcanoes & $\begin{array}{c}\text { No secular trend; occasional eruptions } \\
\text { of up to }-2 \mathrm{Wm}^{-2} \text { global impact }\end{array}$ \\
\hline
\end{tabular}

Additionally, we further divide the radiative forcing into each of the components mentioned above and compute the change in temperature due to each forcing component over the entire period of the temperature record, as well as over shorter periods in the record. This is done by running the model using the values of $\Delta \mathrm{T}_{2 \mathrm{x}}, \mathrm{F}_{\mathrm{A}}$ and $\mathrm{\kappa}$ obtained for the analogous model run using all the radiative forcings, but turning off all radiative forcings except the one we wish to consider, to obtain the temperature change for that individual radiative forcing alone. This is the procedure used by [8]. However, here we include both more recent data and additional sources of radiative forcing that [8] did not include previously.

The shorter periods we consider are: 1904-1944, 1944-1976, 1976-2010 and 1998-2008. The first three periods are those previously examined by [8], which correspond to periods of warming, cooling, and warming, respectively. We also consider 1998-2008, a period during which no warming was observed, a point that is frequently mentioned by skeptics [4]. This has created interest in learning why the temperature did not increase when the radiative forcing by the long-lived greenhouse gases continued to increase [16].

\subsection{Additional Details Regarding the SCM}

This subsection is intended for readers interested in details on the SCM's optimizations and the forcings used.

The SCM calculates the changes in the temperatures of the surface air and ocean, the latter as a function of depth. The ocean is subdivided vertically into 40 layers, with the uppermost being the 67.7-meter-deep mixed layer and the deeper layers each being $100 \mathrm{~m}$ thick. The ocean is subdivided horizontally into a polar region where bottom water is formed, and a nonpolar region where there is upwelling. In the nonpolar region, heat is transported toward the surface by upwelling and downwards by physical processes whose effects are treated as an equivalent diffusion. Heat is also removed from the mixed layer in the nonpolar region by a transport to the polar region and downwelling toward the bottom, this heat being ultimately transported upward from the ocean floor in the nonpolar region. The atmosphere in each hemisphere is subdivided into the atmosphere over the ocean and the atmosphere over land, with heat exchange between them.

We include the changes in carbon dioxide, methane, nitrous oxide [17] and halocarbon [18,19] concentrations in our long-lived greenhouse gas forcing. We convert concentrations to radiative forcing [20].

The tropospheric ozone forcing [21] was used previously by our Group [8]. These are older estimates but are consistent with the best estimate in [22], producing a global-mean tropospheric-ozone forcing at present of $0.39 \mathrm{~W} / \mathrm{m}^{2}$ since pre-industrialization. The ozone forcing partition between hemispheres is the same as that for sulfate aerosol [23].

The SCM includes sulfate aerosol radiative forcing based on the emissions of sulfur dioxide from 1850 to 2005 [23]. We assume that the ratio of the indirect forcing to the direct forcing in a reference year (2000) is $8 / 3$ [24]. Other choices of ratio produce similar values for the total forcing. The indirect portion does not grow exactly linearly with concentration. We use the same formula as previously [25] for the indirect portion, except we use year 2000 rather than 1990 as the reference year.

The black-carbon and organic-carbon radiative forcing includes contributions from fossil and biofuel use $[26,27]$ and open vegetation burning [28]. We assume that the strength of the direct radiative forcing of black carbon in the year 2000 is $-34 / 40$ that of the sulfate aerosols, and that of organic carbon is $+19 / 40$ that of sulfate aerosols. We choose these ratios based on the values reported in the IPCC AR4, Table 2.13 [22]. We assume that the organic-carbon indirect radiative forcing in the reference year is $8 / 3$ of its direct forcing, and the black-carbon indirect forcing is $-8 / 3$ of its direct forcing (hence the black carbon indirect forcing is negative).

We use estimates of global radiative forcing due to land-use changes from [29]. We interpolate between years and extrapolate to the present day. Since the vast majority of the land-use forcing in these estimates has occurred in the Northern Hemisphere, we apply double the globalmean value there, and zero to the Southern Hemisphere.

We include radiative forcing from volcanic eruptions [30]. The data are weighted by a constant of 0.6. We do so to reduce the unrealistically large negative temperature excursions in years following volcanic eruptions in our Group's earlier studies $[8,25]$. Eliminating the volcanic forcing entirely, however, degraded agreement between the simulated and observed interhemispheric temperature difference and oceanic heat content. The value of 0.6 was found to offer the best compromise between these factors. 
We assume the volcanic forcing post-2000 is zero.

The solar irradiance data is from [31,32].

As some of the historical radiative forcing data terminate before 2010, we extend the radiative forcing data based on the trend of the IPCC A1B emissions scenario [33] where necessary for the long-lived greenhouse gases, aerosols, and tropospheric ozone. However this requires extrapolating only for the final few years. Similarly, we extend the solar record based on a fit to the previous three solar cycles; this requires extrapolation for only two years. We assume the volcanic forcing post-1999 is zero, as no eruptions of a scale that altered global climate occurred in the 2000 s.

The timeseries of global-mean radiative forcing for each of the individual sources, as well as the total radiative forcing, are shown in Figure 1. For the long-lived greenhouse-gas forcing, tropospheric ozone forcing, land-use change forcing, forcing due to solar irradiance, and forcing due to volcanic eruptions, the timeseries shown are input to the model.
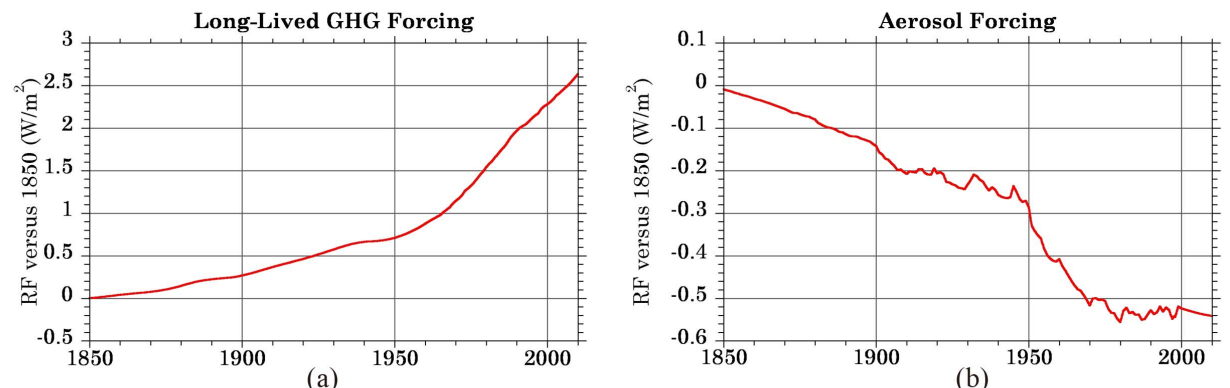

(b)

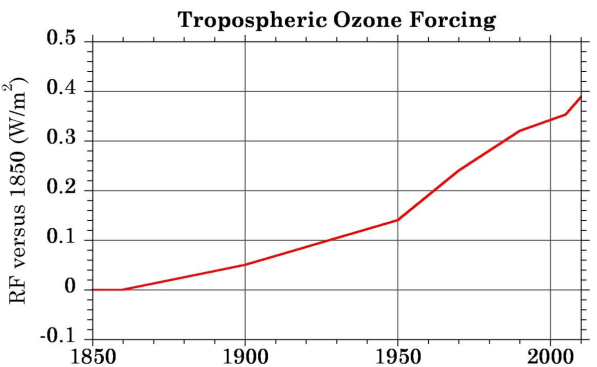

(c)

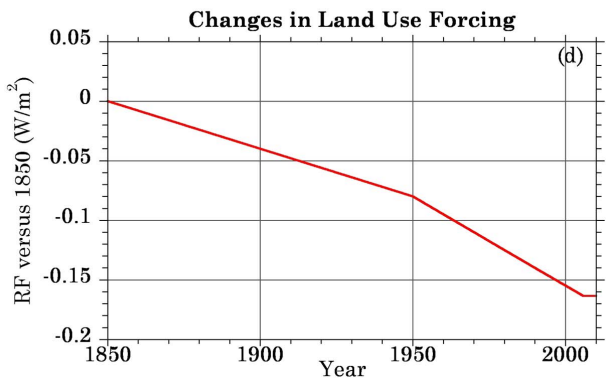

(d)
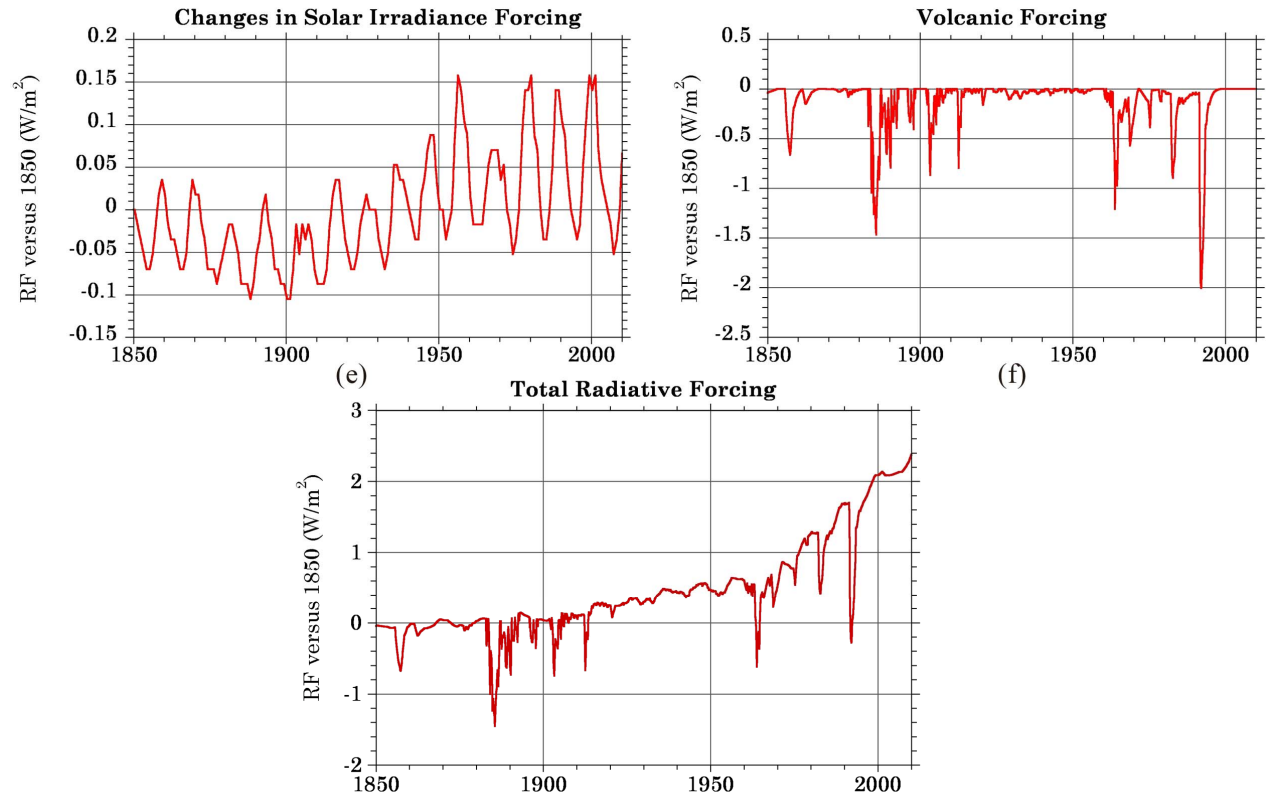

(g)

Figure 1. Global-mean radiative forcing versus 1850 value for each of the following sources: (a) Long-lived greenhouse gases; (b) All aerosols; (c) Tropospheric ozone; (d) Changes in land use; (e) Changes in solar irradiance; (f) Volcanic eruptions; (g) Total of all sources. Aerosol forcing displayed in panel (b) is calculated based on HADCRUT4 optimization for prescribed emissions; all other forcings are prescribed. 
The aerosol radiative forcing shown here is the calculated timeseries of radiative forcing versus time for the HADCRUT4 optimization. Recall that the model optimizes for the strength of the aerosol forcing, so the values obtained for the forcing are not the same in each case. The emissions records used, however, are the same in all cases. The values of aerosol forcing found for NCDC and JMA are more negative, while the values found for GISTEMP are less negative. Also recall that for some of the radiative forcings, the timeseries are different between the Northern and Southern Hemispheres.

In addition to the new sources of radiative forcing considered, we note in particular one major difference between the forcings used here and those used by [8]. The solar record we employ, based on $[31,32]$, contains much less variability with time than the records $[34,35]$ used by [8]. Consequently, the contributions to the temperature changes caused by the changes in solar irradiance that we derive are smaller than those that our Group found previously.

The model seeks to optimize values of equilibrium climate sensitivity, $\Delta \mathrm{T}_{2 \mathrm{x}}$, direct sulfate radiative forcing, $\mathrm{F}_{\mathrm{ASA}}$, and ocean diffusivity $\kappa$. The optimized solution is obtained by minimizing the root-mean-square error (RM$\mathrm{SE})$ for the length of each instrumental temperature record (1850-2010 for HADCRUT4, 1880-2010 for GISTEMP and NCDC, 1891-2010 for JMA) between the simulated and observed: 1) global temperatures with respect to $\Delta \mathrm{T}_{2 \mathrm{x}} ; 2$ ) interhemispheric temperature differences with respect to $\mathrm{F}_{\mathrm{ASA}}$; and 3) upper oceanic heat content [15] with respect to $\kappa$. The model begins by calculating simulated global temperature, interhemispheric temperature difference and ocean heat uptake records for initial choices of $\Delta T_{2 x}, F_{A S A}$, and $\kappa$ and determining the RMSE for each simulation as compared to the observed. The process continues by re-calculating the simulated records for different guesses of $\Delta \mathrm{T}_{2 \mathrm{x}}, \mathrm{F}_{\mathrm{ASA}}$, and $\kappa$ and comparing the RMSE values obtained for the new guess to those for the old guesses. The iteration is continued until the point is found where the partial derivative of the RMSE between simulated and observed global temperature with respect to choice of $\Delta \mathrm{T}_{2 \mathrm{x}}$, the partial derivative of RMSE between simulated and observed interhemispheric temperature difference with respect to $\mathrm{F}_{\mathrm{ASA}}$, and the partial derivative of RMSE between simulated and observed ocean heat anomalies with respect to $\kappa$, are all zero. The values of $\Delta \mathrm{T}_{2 \mathrm{x}}, \mathrm{F}_{\mathrm{ASA}}$, and $\kappa$ that meet these conditions on the partial derivatives are taken as the model's solution. For each case we performed the optimization for several different initial guesses of $\Delta \mathrm{T}_{2 \mathrm{x}}, \mathrm{F}_{\mathrm{ASA}}$, and $\kappa$ to insure that the solutions we obtained are robust.

\subsection{Singular Spectrum Analysis}

SSA [36] is a non-parametric spectral estimation method that is similar to Fourier analysis. Unlike Fourier analysis, which is restricted to sinusoidal basis functions, SSA permits basis functions to have any form, finding functions which best match the data considered. While the functions found are often oscillatory, there is no requirement that they have constant amplitude or period, as they must in Fourier analysis. Hence these functions are called "quasi-periodic oscillations" (QPOs). The most prominent of these QPOs is the Atlantic Multidecadal Oscillation (AMO), which has a period of 65 - 70 years [1]. Additional details regarding the SSA procedure may be found in [37], whose procedure we follow, except that we do not first detrend the instrumental temperature records.

In addition to the QPOs, non-oscillatory principal components (PCs), or functions that express the variability in time of the data considered, may also be found. (If the data are first detrended as in [37] these modes will not appear). In our analyses [38] these non-oscillatory modes are the two leading PCs in each of the four instrumental datasets, meaning they explain more of the variability than the other modes. We shall call the combination of these two leading non-oscillatory PCs the "SSA-Trend", which does not contain any of the internal variability represented by the previously described QPOs. Instead, the temperature changes represented by the SSA trend must either be externally forced, or part of a yet undiscovered oscillation with a period longer than half of the record length.

The SSA temperature trend and the SCM-simulated temperature changes are determined independently of each other. The SSA trend contains no information on the factors that caused it, either by nature alone-volcanoes and variations in solar irradiance-or humanity, while the temperature changes simulated by the SCM are forced by natural factors alone or by anthropogenic plus natural factors. If the SCM is unable to reproduce the SSA trend using only the natural radiative forcing but is able to reproduce the SSA trend using anthropogenic plus natural radiative forcings, this is strong evidence that the anthropogenic forcings are the cause of the rising temperature trend found by SSA and not a yet undiscovered long-period QPO.

We use the QPOs determined through SSA to understand more fully the contributions of the modes of internal variability to the temperature changes. For both the overall length of the temperature record and for the four shorter individual time periods we consider, we determine the amount of temperature change due to each statistically significant QPO.

\section{Results}

We compare the SSA trend found for each of the four 
instrumental temperature datasets over the entire period to the global-mean temperature increase simulated by the Simple Climate Model (SCM). We also consider the temperature changes caused by each forcing and QPO over five other periods. Additionally, we examine the changes since [8] in the estimates of: 1) the climate sensitivity - the change in global-mean, equilibrium nearsurface temperature for a radiative forcing equivalent to a doubling of the pre-industrial $\mathrm{CO}_{2}$ concentration $\left(\Delta \mathrm{T}_{2 \mathrm{x}}\right)$; and 2) the total aerosol radiative forcing in reference year $2000\left(\mathrm{~F}_{\mathrm{A}}(2000)\right)$.

\subsection{Causes of the Warming over the Entire Instrumental Record}

The four observed temperature datasets are shown in Figure 2. For each dataset the leading two PCs found by SSA combine to form a trend of about $0.8^{\circ} \mathrm{C}$ over the duration of each observed record. The trend found for HADCRUT4 increases continuously after 1880 , while the trends found for the GISTEMP, NCDC and JMA
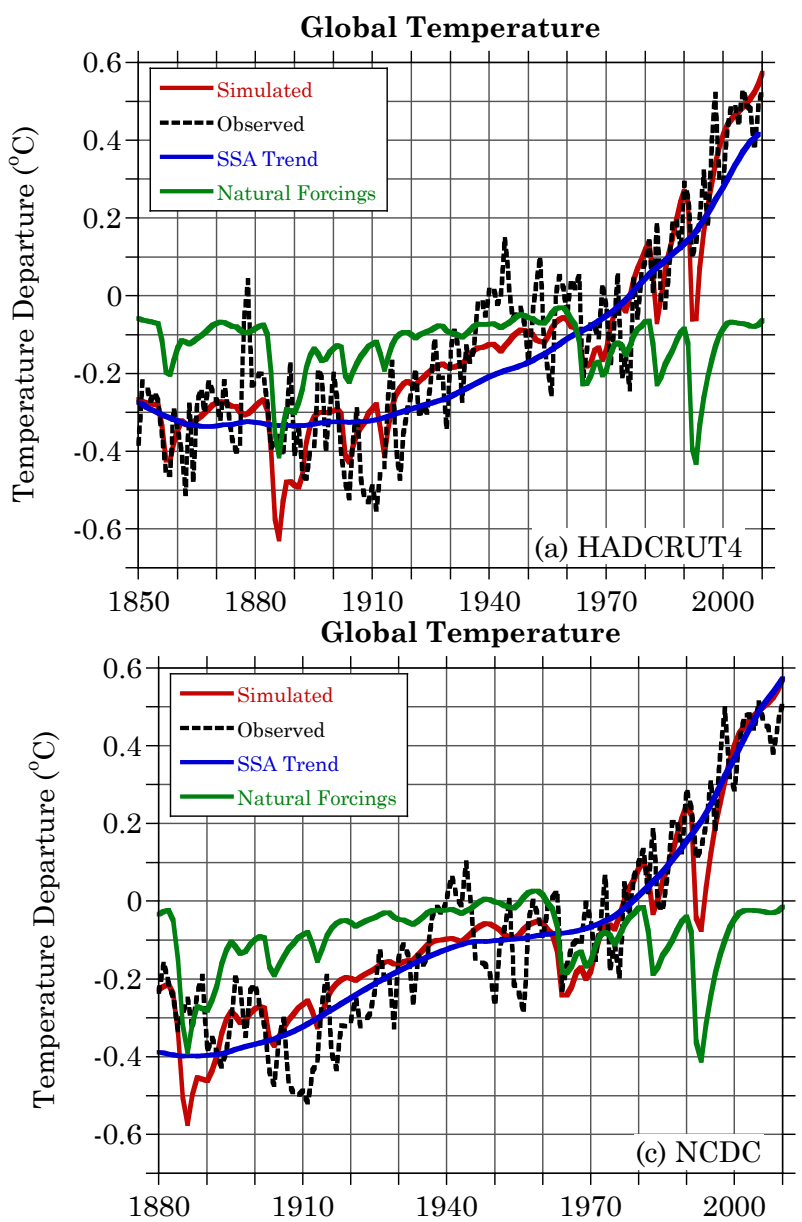

datasets display a plateau in the mid-20th century, with the temperature increase occurring before and after that period.

The temperature changes simulated by the SCM when all forcings are included, shown in Figure 2, also display an increase of $0.8^{\circ} \mathrm{C}$ over the duration of each of the four observational datasets. The simulated data, unlike the SSA trend, include higher-frequency variations, includeing the negative temperature excursions caused by volcanic eruptions.

Coefficients of determination - the square of the correlation coefficient between two timeseries, $\mathrm{R}^{2}$-are presented in Table 2 for each dataset, with $\mathrm{R}^{2}=1$ indicating perfect correlation, $\mathrm{R}^{2}=0$ indicating no correlation and $\mathrm{R}^{2}<0$ indicating anti-correlation. As seen in Table 2, there is a strong correlation between the SSA trend and the observations for all four datasets. The agreement between the SCM simulations when all forcings are included and the observations, and between these simulations and SSA trend, is also high.
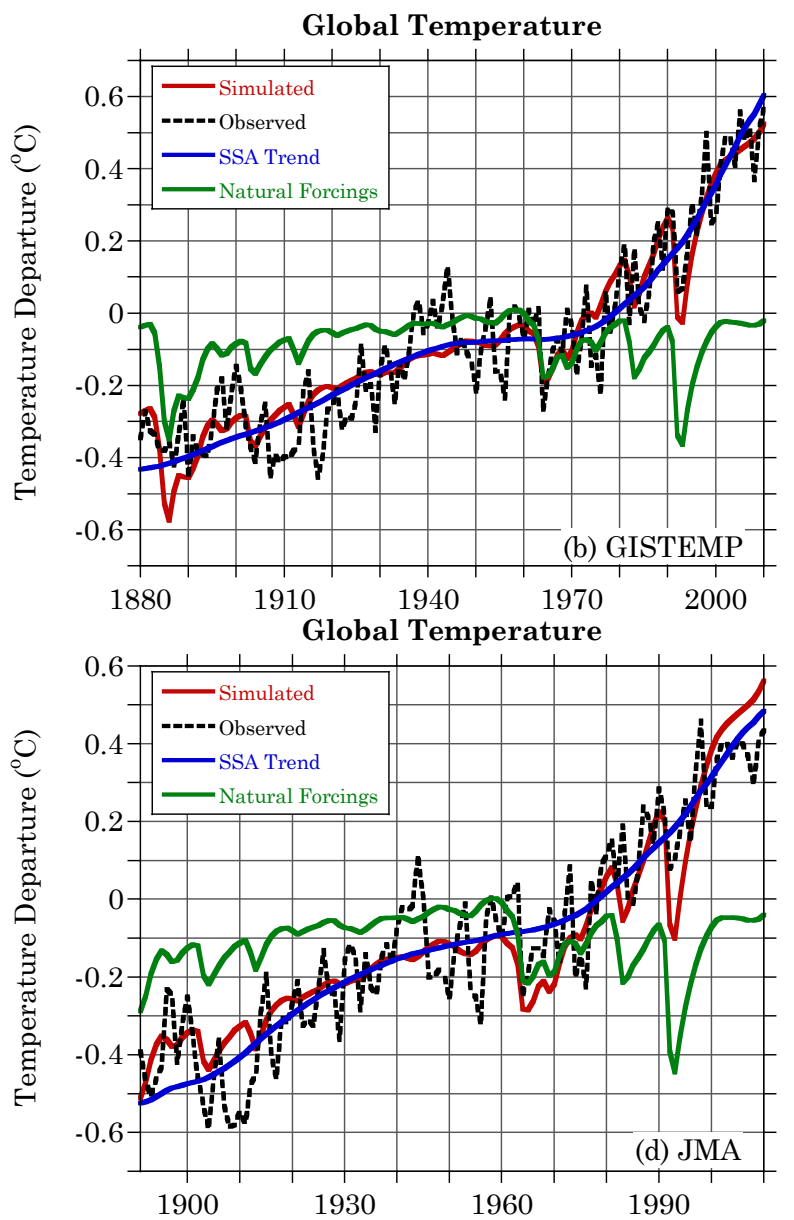

Figure 2. Observed global-mean near-surface temperature (black), and its trend derived from SSA (blue), together with the SCM-simulated temperature changes using all forcings (red) and natural forcings alone (green), for the HADCRUT4 (a), GISTEMP (b), NCDC (c), and JMA (d) temperature records. Temperatures are shown as departures from the 1961-1990 mean. 
In contrast, the SCM simulations using only the natural forcings do not replicate the observed increase in temperature. Instead, the simulated temperature under these conditions is roughly constant over time, with negative excursions noted in the years immediately following volcanic eruptions. $\mathrm{R}^{2}$ values for both the SCM simulations without anthropogenic forcing and observations, and for these simulations and the SSA trend, are very low. The failure of the SCM to replicate the observed warming when only natural forcings are used is similar to the behavior of coupled general circulation models examined in IPCC AR4 [39].

The simulation results presented in Figure 2 and Table 2 for natural forcing alone are for the value of $\Delta T_{2 x}$ determined under the influence of all forcings. We performed SCM simulations for natural forcings alone and tried to estimate $\Delta \mathrm{T}_{2 \mathrm{x}}, \mathrm{F}_{\mathrm{A}}(2000)$ and $\kappa$ as described above, but no solution was found. Accordingly we performed simulations with these quantities prescribed over a wide range, with $\Delta \mathrm{T}_{2 \mathrm{x}}$ as large as $10,000^{\circ} \mathrm{C}$ and as small as $0.1^{\circ} \mathrm{C}$, to compare with the observations. None of the simulated temperature records produced thereby matches the observed temperature increase, the SSA trend, or the temperature increase simulated by the SCM when anthropogenic forcing is included. Thus the increase in global-mean near-surface temperature is not due to externally forced natural variability. While the difference between the observed temperatures and both the SSA trend and the SCM-calculated temperature changes indicates the presence of internal natural variability, this is not the cause of the global warming observed since the 19th century. This confirms [8]'s finding that human activities are the main cause of the observed warming over the total length of the instrumental temperature records.

Figure 3 indicates the contribution to the observed temperature change for each of the external forcings and QPOs over the entirety of each temperature record. We examine separately the contributions from the long-lived greenhouse gases (LLGHGs), the aerosols, volcanic eruptions, the sum of the statistically significant QPOs, and the stochastic noise - that is, the portion of the temperature record that cannot be explained by either the trend found through SSA, or the statistically significant QPOs. We also display as "other" the change in temperature that cannot be accounted for using the sources explicitly examined above. This includes the contributions from the solar, land-use, and tropospheric-ozone forcing,

Table 2. Coefficient of Determination, $\mathbf{R}^{2}$, for Global-Mean Temperature.

\begin{tabular}{|c|c|c|c|c|}
\hline \multirow{2}{*}{$\begin{array}{l}\text { Quantities } \\
\text { Compared }^{\text {a }}\end{array}$} & \multicolumn{3}{|c|}{ Observational Dataset } & \multirow[b]{2}{*}{ JMA } \\
\hline & HADCRUT4 & GISTEMP & NCDC & \\
\hline $\begin{array}{l}\text { (a) SSA Trend and } \\
\text { Observed }\end{array}$ & 0.77 & 0.86 & 0.84 & 0.85 \\
\hline $\begin{array}{l}\text { (b) Sim (All) and } \\
\text { Observed }\end{array}$ & 0.81 & 0.85 & 0.81 & 0.81 \\
\hline $\begin{array}{l}\text { (c) Sim (All) and } \\
\text { SSA Trend }\end{array}$ & 0.84 & 0.94 & 0.92 & 0.90 \\
\hline $\begin{array}{l}\text { (d) Sim (Nat) and } \\
\text { Observed }\end{array}$ & 0.02 & 0.06 & 0.01 & -0.01 \\
\hline $\begin{array}{l}\text { (e) Sim (Nat) and } \\
\text { SSA Trend }\end{array}$ & 0.05 & 0.04 & 0.02 & -0.03 \\
\hline
\end{tabular}

$\overline{\mathrm{a} O b s=\text { Observations, } \mathrm{Sim}=\text { Simulation, All = natural plus anthropogenic }}$ radiative forcing, Nat $=$ natural radiative forcing alone.
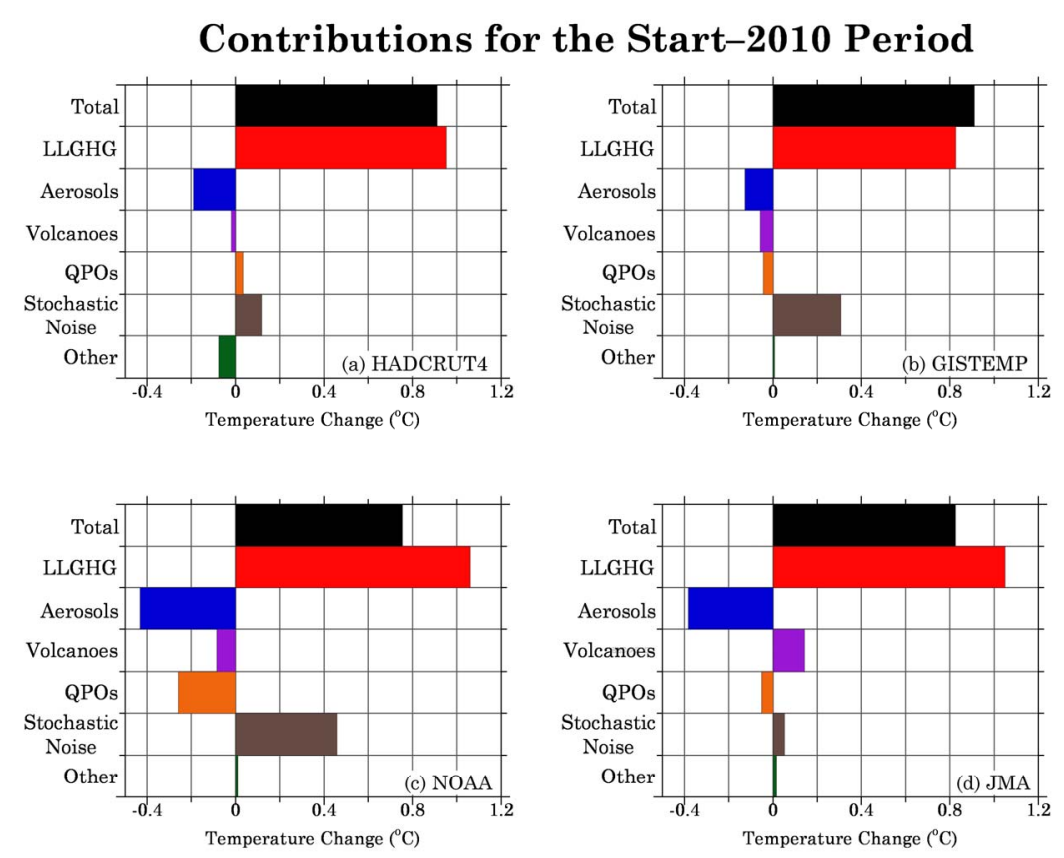

Figure 3. Contributions of each factor to the observed temperature increase from the beginning of each instrumental record to 2010, for the (a) HADCRUT4, (b) GISTEMP, (c) NOAA, and (d) JMA instrumental records. 
the other three external forcings used by the SCM. These sources of forcing produce temperature changes that are much smaller than the other sources.

The individual factor agreeing most closely with the magnitude of the total temperature change is the contribution from long-lived greenhouse gases (LLGHGs). In three of the four cases, the LLGHG contribution exceeds the total temperature change, indicating that the sum of the other contributions must act to decrease the temperature change. The largest contribution in this negative direction is the strength of the aerosol forcing; its magnitude is larger for the runs based on the NOAA and JMA datasets since the SCM finds a more negative $\mathrm{F}_{\mathrm{A}}(2000)$ for these two runs as compared to HADCRUT4 and GISTEMP.

The contributions from the statistically significant QPOs are smaller than the LLGHG contribution over the entire instrumental time periods. This is expected since even the strongest QPO has an amplitude of only $0.1^{\circ} \mathrm{C}$, which is almost an order of magnitude smaller than the observed $0.8^{\circ} \mathrm{C}$ of temperature change [19]. Also, the longest-period QPO, the AMO, has a period of about 70 years, whereas we are examining records that are over a century long.

The action of the QPOs varies among the four datasets. As noted above, the number of statistically significant QPOs found for each observational dataset, as well as the amplitudes and periods of those that are found, are not identical. Additionally, we note that the start dates of the four temperature records are different -1850 for HADCRUT4, 1880 for GISTEMP and NOAA, 1891 for JMA. These two factors account for the different behavior of the QPO contribution among the datasets.

The volcanic eruptions make a negative contribution to the temperature change for three of four datasets, while they make a positive contribution for the JMA case. The starting years for the HADCRUT4, GISTEMP, and NOAA temperature observations are before the Krakatoa volcano eruption in 1883 . The simulated temperature changes due to volcanoes alone for these starting years are higher than they are for end year 2010. Thus, the temperature changes from the starting year to 2010 due to volcanoes are negative for these three cases. The starting year for the JMA temperature observations is 1891, after the Krakatoa volcano eruption in 1883. The simulated temperature change for this starting year due to volcanoes is lower than it is for 2010. Thus, the temperature change from the starting year to 2010 due to volcanoes is positive for the JMA dataset. Changing the starting year of the other three temperature datasets to 1891 also causes the volcanic contribution to become positive.

While the LLGHGs from human activities are the main cause of the warming over the total period of the four records, they are not necessarily the major cause of the observed temperature changes over shorter periods.
Accordingly, we next consider the individual contributions of each of the external forcings and the QPOs to the observed temperature change for the four shorter time periods mentioned previously.

\subsection{Causes of the Early 20th Century Warming: 1904-1944}

In Figure 4 we examine the contributions to the temperature change over the 1904-1944 period. While this is a period of observed warming, [8] found that the LLGHG forcing was only a secondary factor during this period, with internal variability being the most important contributor to the warming (see their Figure 4). We confirm their findings here: while between $0.53^{\circ} \mathrm{C}$ to $0.71^{\circ} \mathrm{C}$ of warming is found in the instrumental records, only $0.13^{\circ} \mathrm{C}$ to $0.17^{\circ} \mathrm{C}$ of this warming is due to LLGHG forcing. By contrast the sum of the statistically significant QPOs ranges from $0.16^{\circ} \mathrm{C}$ for GISTEMP to $0.34^{\circ} \mathrm{C}$ for HADCRUT4. The stochastic noise also contributes positively over this period for each record, with values ranging from $0.11^{\circ} \mathrm{C}$ for HADCRUT4 to $0.24^{\circ} \mathrm{C}$ for JMA.

An additional notable contribution is from volcanic forcing, which produces between $0.11^{\circ} \mathrm{C}$ to $0.13^{\circ} \mathrm{C}$ of warming. Since the early 20th century was a period with few volcanic eruptions, while the late 19th century was a volcanically active period, the 1904-1944 period is associated with a decrease of volcanically produced aerosols and hence a warming effect due to the smaller number of large volcanic eruptions [40].

\subsection{Causes of the Mid-20th Century Cooling: 1944-1976}

We next examine 1944-1976, the period of mid-century cooling, and display results in Figure 5. Our findings are again consistent with those of [8] that natural causes are the main driver during this period. While the analyses for all four records include negative aerosol forcing over this period, the magnitude of the positive LLGHG forcing exceeds that of the negative aerosol forcing in each case. The other two sources of human forcing we consider, tropospheric ozone and land-use changes, are only minor contributors. Hence, the total human contribution to the temperature change is positive over this period, in contrast to the observed negative changes. We also note that volcanic eruptions produce a contribution of $-0.09^{\circ} \mathrm{C}$ to $-0.06^{\circ} \mathrm{C}$ in all four datasets.

In all four cases the contribution of the statistically significant QPOs is negative with values ranging from $-0.31^{\circ} \mathrm{C}$ to $-0.20^{\circ} \mathrm{C}$. The $\mathrm{AMO}$ produces a negative contribution to the temperature change, with its magnitude again being largest in the HADCRUT4 analysis. The other QPOs also contribute to the decline, as does the stochastic noise in all four cases. 

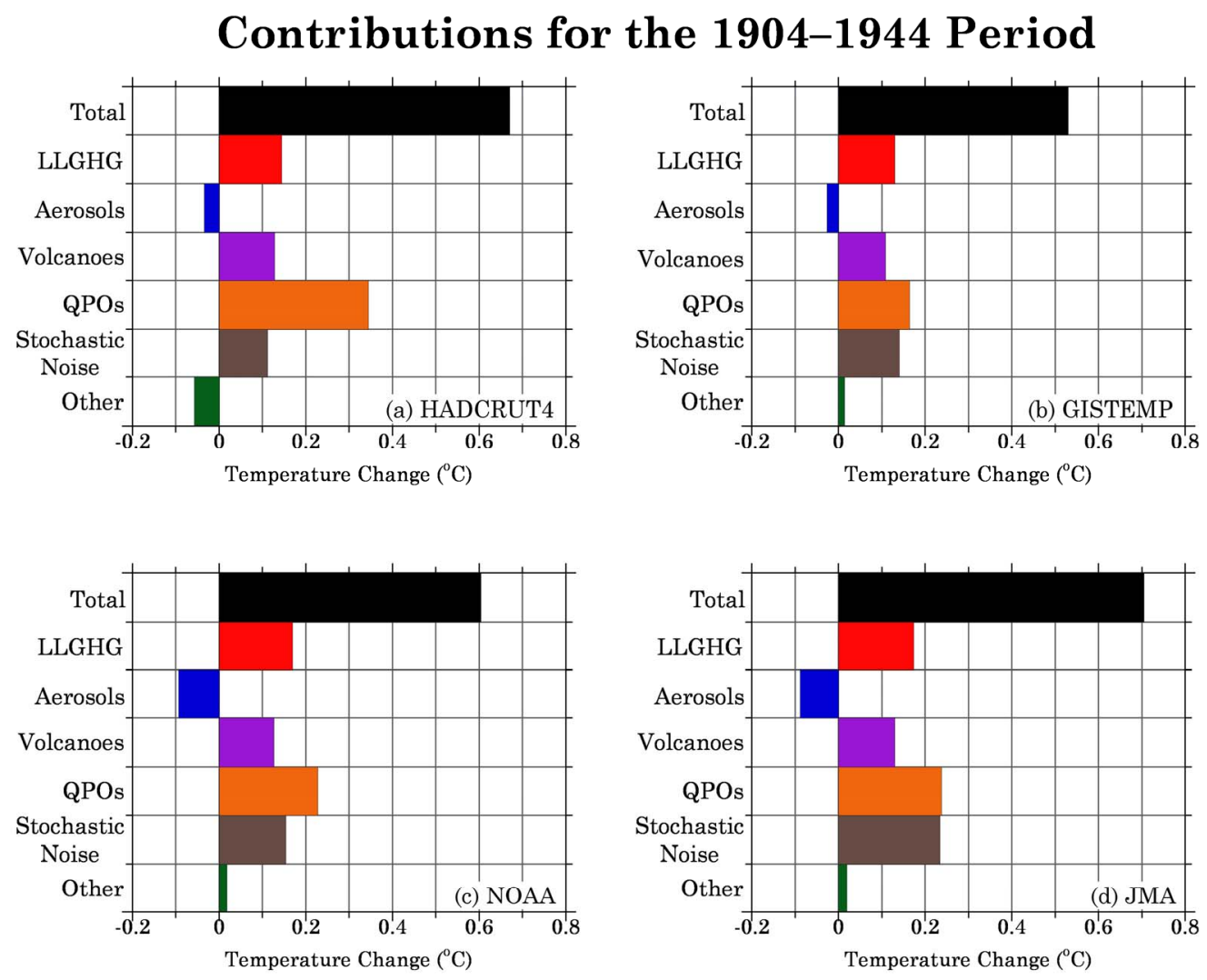

Figure 4. As in Figure 3, but for the 1904-1944 period.

\section{Contributions for the 1944-1976 Period}
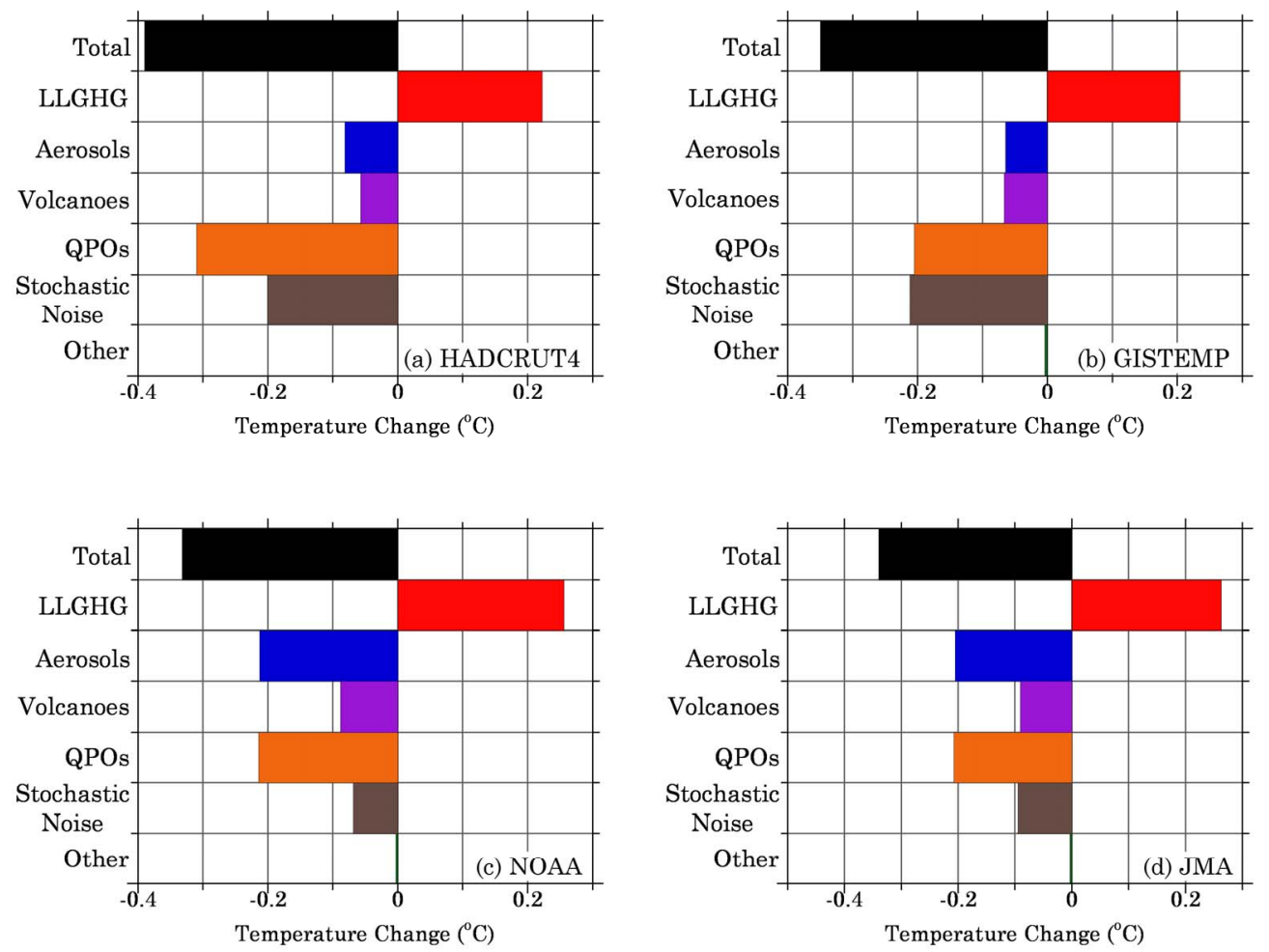

Figure 5. As in Figure 4, but for the 1944-1976 period. 


\subsection{Causes of the Late 20th-Early 21st Century Warming: 1976-2010}

In Figure 6 we examine the contributions over the 1976-end period. [8] considered the 1976-1990 period and found human forcing and internal variability to be roughly co-equal factors in explaining the warming. With the additional 20 years of data we find that the LLGHG forcing is the dominant cause of the warming in the 1976-2010 period. The LLGHG forcing produces between $0.43^{\circ} \mathrm{C}$ to $0.57^{\circ} \mathrm{C}$ of warming, depending on the dataset, while the observed temperature increase over this period ranges from $0.66^{\circ} \mathrm{C}$ to $0.79^{\circ} \mathrm{C}$. Thus, a majority of the recent warming is explained by the LLGHG forcing. The secondary contribution to the observed warming comes from the internal variability, with the stochastic noise being particularly notable for HADCRUT4, GISTEMP and NOAA. In contrast, the stochastic-noise contribution for JMA is nearly zero. The changes caused by the aerosols, volcanoes, and other external forcings in this period are also essentially zero.

\subsection{Causes of the 1998-2008 Cooling}

Finally, we examine in Figure 7 the contributions to the temperature changes between 1998 and 2008, a period in which the global-mean temperature cooled by between $0.11^{\circ} \mathrm{C}$ to $0.22^{\circ} \mathrm{C}$, depending on the dataset. The temperature changes due to LLGHGs and volcanoes are positive, the latter because of the recovery from the cooling caused by the eruption of the Pinatubo volcano in 1991. We note in particular that the aerosol contribution during this period is virtually zero for all four datasets, a finding which contradicts [16]. However, the sulfur dataset we use [22] features an emissions decrease between 1998 and 2001 in addition to an increase from 2001 to 2005. As the emissions are not unidirectional over this period, the impact from the increased sulfur emissions post-2001 is lessened.

The internal variability is responsible for the temperature decrease observed during 1998-2008. The contributions vary by dataset. In HADCRUT4, GISTEMP, and NOAA, the QPO contribution is $-0.22^{\circ} \mathrm{C},-0.27^{\circ} \mathrm{C}$ and $-0.19^{\circ} \mathrm{C}$ respectively. In JMA a much weaker contribution of $-0.08^{\circ} \mathrm{C}$ is found. The stochastic-noise contribution $\left(-0.31^{\circ} \mathrm{C}\right)$ is dominant in JMA, but is smaller in HADCRUT4 and NOAA (about $-0.15^{\circ} \mathrm{C}$ in each) and nearly zero in GISTEMP.

\subsection{Changes in Estimates of Climate Sensitivity and Aerosol Forcing}

While our results show that human factors are the most important drivers of climate change over the entirety of the instrumental records, and the post-1976 period, our estimates of $\Delta \mathrm{T}_{2 \mathrm{x}}$ are lower than our previous estimates. Table 3 shows that the cumulative changes to our analysis procedure from that of [8], which analyzed an earlier version of the HADCRU temperature record [41], have decreased the estimate of $\Delta \mathrm{T}_{2 \mathrm{x}}$ from $2.5^{\circ} \mathrm{C}$ to $1.6^{\circ} \mathrm{C}$.

\section{Contributions for the 1976-2010 Period}
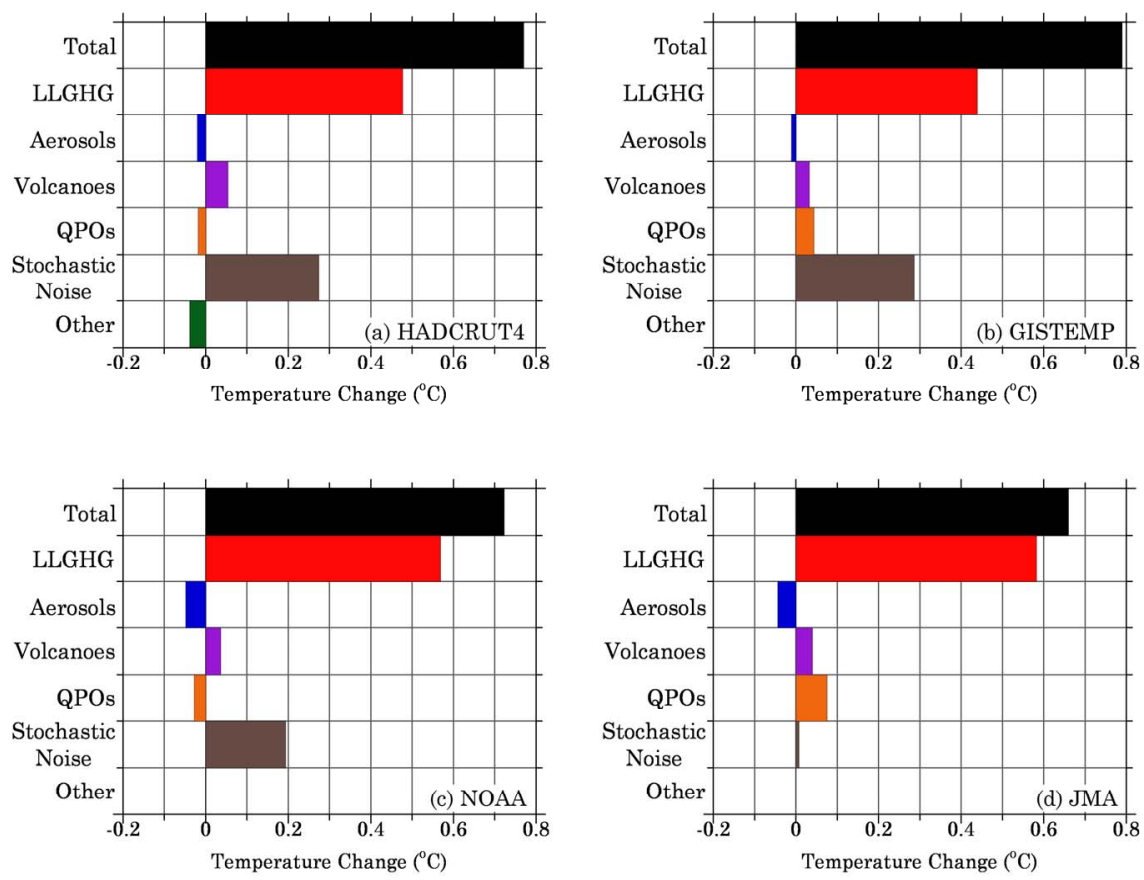

Figure 6. As in Figure 5, but for the 1976-2010 period. 


\section{Contributions for the 1998-2008 Period}
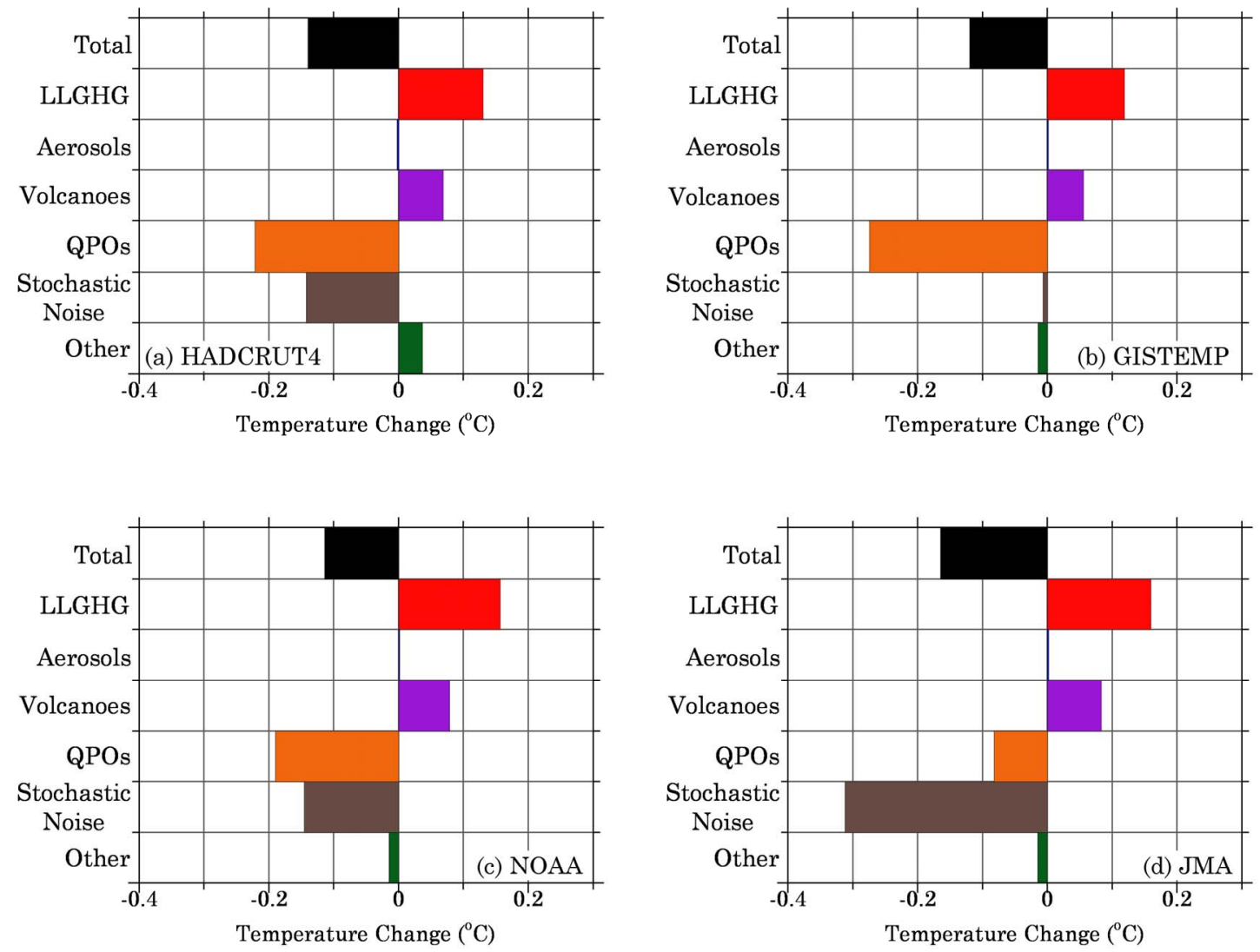

Figure 7. As in Figure 6, but for the 1998-2008 period.

Table 3. Index of changes to the SCM and their effects on estimation of $\Delta T_{2 x}$.

\begin{tabular}{|c|c|c|}
\hline Item & $\begin{array}{l}\Delta \mathrm{T}_{2 \mathrm{x}} \text { for Cumulative } \\
\text { Changes }\left({ }^{\circ} \mathrm{C}\right)\end{array}$ & $\begin{array}{c}\text { Cumulative Change in } \\
\Delta \Delta \mathrm{T}_{2 \mathrm{x}}\left({ }^{\circ} \mathrm{C}\right)\end{array}$ \\
\hline Andronova \& Schlesinger (2000) & 2.5 & \\
\hline Replace Jones et al. (1999) temperature record by HADCRUT3 & 2.0 & -0.5 \\
\hline $\begin{array}{l}\text { Replace Harvey et al. (1997) } \mathrm{SO}_{2} \text { emission record by Smith et al. (2011) } \mathrm{SO}_{2} \text { emission re- } \\
\text { cord but keep } 80 / 20 \text { division between hemispheres }\end{array}$ & 2.0 & -0.5 \\
\hline Use the actual division of emissions between hemisphere for each year & 1.8 & -0.7 \\
\hline Extend beginning of SCM comparison from 1856 to 1850 & 2.0 & -0.5 \\
\hline $\begin{array}{l}\text { Replace Lean et al. (1995) solar forcing by Wang et al. (2005) \& Lean et al. (2005) solar } \\
\text { forcing }\end{array}$ & 2.7 & 0.2 \\
\hline Add radiative forcing due to black-carbon aerosol and organic-carbon aerosol & 3.2 & 0.7 \\
\hline Add radiative forcing due to land-use changes & 3.1 & 0.6 \\
\hline Extend SCM termination year from 1997 to 2010 & 2.7 & 0.2 \\
\hline $\begin{array}{l}\text { Correct code error ( } 3 \mathrm{~N} \text {. hemispheric coefficients in a S. hemispheric equation) \& recalibrate } \\
\text { SCM using the observed annual cycle as done previously }\end{array}$ & 1.8 & -0.7 \\
\hline Weight volcanic radiative forcing by 0.6 & 1.9 & -0.6 \\
\hline Include ocean heat uptake as a constraint & 1.6 & -0.9 \\
\hline Replace HADCRUT3 with HADCRUT4 & 1.6 & -0.9 \\
\hline
\end{tabular}


The climate sensitivity, $\Delta \mathrm{T}_{2 \mathrm{x}}$, for each of the four datasets is presented in Table 4, together with the corresponding total aerosol radiative forcing, $\mathrm{F}_{\mathrm{A}}(2000)$ and oceanic thermal diffusivity $\kappa$. The $\Delta \mathrm{T}_{2 \mathrm{x}}$ estimates for the four datasets range from $1.45^{\circ} \mathrm{C}$ to $2.01^{\circ} \mathrm{C}$. These values are on the low side of the range given in the IPCC Fourth Assessment Report [42]. The values for aerosol forcing and diffusivity are consistent with other estimates of these quantities from observed data [43].

\section{Discussion}

We have found that human activities, and in particular the radiative forcing related to LLGHGs, are the dominant cause of the warming observed since the beginning of the instrumental temperature records in the 19th century, and the most recent global warming from the mid-1970s through 2010. This confirms the results of [8]. A number of other studies have also found that human forcing has caused most of the late-20th century warming. These include studies using coupled atmosphere-ocean general circulation models [44-48], as well as studies using simpler models such as energy-balance models [43, 49-51]. Most notably, the addition of the 1990-2010 period in our current study increases the proportion of recent warming attributable to human causes as compared to [8].

There is a stronger diversity of views about the causes of the early 20th century warming. Our present study agrees with [8] that human causes are a secondary factor during this period, with natural causes being the primary driver over the 1904-1944 period. Other studies have also found that natural causes are mainly responsible over this period, with some studies finding important roles for solar irradiance changes [46,47,52], volcanic eruptions $[40,52,53]$, or internal variability $[44,53]$ over this period.

We find that of these three factors - natural variability, volcanic eruptions, and solar irradiance, natural variability is the most important contributor to the temperature increase over this period. While this time period is notable for an increasing amplitude in the AMO [1], the stochastic noise is an important internal contributor as well

Table 4. Estimates of climate sensitivity, $\Delta \mathbf{T}_{2 \mathrm{x}}$, total aerosol forcing for year $2000, F_{A}$, and oceanic thermal diffusivity $\kappa$ based on each instrumental dataset.

\begin{tabular}{cccc}
\hline Instrumental Dataset & $\Delta \mathrm{T}_{2 \mathrm{x}}\left({ }^{\circ} \mathrm{C}\right)$ & $\mathrm{F}_{\mathrm{A}}\left(\mathrm{W} \cdot \mathrm{m}^{-2}\right)$ & $\kappa\left(\mathrm{cm}^{2} \cdot \mathrm{s}^{-1}\right)$ \\
\hline GISTEMP & 1.45 & -0.42 & 0.33 \\
HADCRUT4 & 1.61 & -0.52 & 0.30 \\
NOAA & 1.99 & -0.99 & 0.31 \\
JMA & 2.01 & -0.89 & 0.27 \\
\hline
\end{tabular}

over this period. Volcanic eruptions are a notable seconddary factor, approximately on par with the LLGHG contribution over this period. In contrast to several earlier studies, we find that changes in solar irradiance produce only a very small contribution over this period-about a few hundredths of a degree Celsius. However, the solar irradiance record used here, based on [31,32], is much less variable than many of the earlier records used by $[34,35]$, so the small solar contribution here and larger contribution from other studies using the older records are not inconsistent.

One of the most important reasons to pursue the simple approach that we have chosen here is to make the results accessible to those without a scientific background. Therefore we reflect briefly on the policy implications of our results.

Most importantly, the results over the entire period of the instrumental records demonstrate that the contribution from the LLGHG forcing is responsible for the observed temperature increase. While internal variability may be critical during shorter periods, the sum of the QPOs' contributions over the entirety of the temperature record is small compared to the LLGHG forcing. As discussed above, the contribution from variations in solar irradiance is also small. The aerosol forcings, of course, cannot account for the warming since they have had a cooling tendency. Since human emissions are responsible for the observed temperature increase, additional future emissions will add even more radiative forcing to the climate system. Therefore, in contrast to the claims of climate skeptics, emissions reductions are in fact needed to reduce future climate forcing and future warming.

Additionally, our estimates of climate sensitivity using our SCM and the four instrumental temperature records range from about $1.5^{\circ} \mathrm{C}$ to $2.0^{\circ} \mathrm{C}$. These are on the low end of the estimates in the IPCC's Fourth Assessment Report. So, while we find that most of the observed warming is due to human emissions of LLGHGs, future warming based on these estimations will grow more slowly compared to that under the IPCC's "likely" range of climate sensitivity, from $2.0^{\circ} \mathrm{C}$ to $4.5^{\circ} \mathrm{C}$. This makes it more likely that mitigation of human emissions will be able to hold the global temperature increase since pre-industrial time below $2^{\circ} \mathrm{C}$, as agreed by the Conference of the Parties of the United Nations Framework Convention on Climate Change in Cancun [54]. We find with our SCM that our Fair Plan to reduce LLGHG emissions from 2015 to 2065, with more aggressive mitigation at first for industrialized countries than developing countries, will hold the global temperature increase below $2^{\circ} \mathrm{C}$ [55].

Although we believe, given our relatively low values for equilibrium climate sensitivity, that the $2^{\circ} \mathrm{C}$ goal is 
attainable, we emphasize that steep emissions cuts must begin now in order to reach this goal. It is a temptation among members of the general public and even more highly educated adults outside the climate sciences [56], that $\mathrm{CO}_{2}$ concentrations can be stabilized simply by stabilizing our present emissions, or that a drop in $\mathrm{CO}_{2}$ emissions would quickly cause a drop in global temperature. Climate scientists of course know that the large imbalance between current $\mathrm{CO}_{2}$ emissions and natural removal processes, and the long resident lifetime of $\mathrm{CO}_{2}$ in the atmosphere, render the "wait-and-see" approach impossible and dangerous. Mitigation of human-caused climate change requires immediate corrective action.

\section{Conclusions}

We have used two methods-Singular Spectrum Analysis (SSA) of the instrumental temperature records and simulations using our Simple Climate Model (SCM) - to investigate the causes of the global temperature increase since the instrumental records began in the 19th century, and for selected shorter periods within the instrumental records. The two leading modes produced by SSA combine to form a trend of about $0.8^{\circ} \mathrm{C}$ since pre-industrialization, matching the observed increase. Simulations using our SCM also produce an increase of about $0.8^{\circ} \mathrm{C}$ when anthropogenic forcings are included, but are unable to produce an increase when natural forcings alone are used. Thus, human forcings are the primary cause of the warming observed since the 19th century. Human forcing is also the primary cause of the warming observed since 1976. However, the warming during 1904-1944 and subsequent cooling during 1944-1976 were caused predominantly by natural internal variability in the climate system.

In this study we have chosen simple methods in order to make our results more accessible to other scientists and the general public. Our findings have confirmed that human emissions are the main cause of the global warming over the past 150 years. Since human emissions are the cause of the global warming, reducing emissions will reduce the amount of warming in the future. We hope this study contributes to a public realization that emissions reductions are necessary to safeguard Earth's climate.

\section{Acknowledgements}

This work was funded by the United States National Science Foundation grant ATM 08-06155. Any opinions, findings, and conclusions or recommendations expressed in this material are those of the authors and do not necessarily reflect the views of the National Science Foundation.

\section{REFERENCES}

[1] M. E. Schlesinger and N. Ramankutty, "An Oscillation in the Global Climate System of Period 65-70 Years," Nature, Vol. 367, 1994, pp. 723-726. doi:10.1038/367723a0

[2] IPCC, "Policymakers' Summary," In: J. T. Houghton, G. J. Jenkins and J. J. Ephraums, Eds., Climate Change: The IPCC Scientific Assessment, Cambridge University Press, Cambridge, 1990.

[3] IPCC, "Summary for Policymakers," In: S. Solomon, et al., Eds., Climate Change 2007: The Physical Science Basis, Cambridge University Press, Cambridge, 2007.

[4] S. F. Singer, Ed., "Nature, Not Human Activity, Rules the Climate: Summary for Policymakers of the Report of the Nongovernmental International Panel on Climate Change," Heartland Institute, Chicago, 2008.

[5] Gallup, “Gallup Poll Social Series: Environment,” 2011. http://www.gallup.com/poll/146606/concerns-global-war ming-stable-lower-levels.aspx

[6] G. C. Hegerl and F. Zweirs, "Use of Models in Detection and Attribution of Climate Change," Wiley Interdisciplinary Reviews: Climate Change, Vol. 2, No. 4, 2011, pp. 570-591. doi:10.1002/wcc. 121

[7] International Ad Hoc Detection and Attribution Group, "Detecting and Attributing External Influences on the Climate System: A Review of Recent Advances," Journal of Climate, Vol. 18, No. 9, 2005, pp. 1291-1314. doi:10.1175/JCLI3329.1

[8] N. G. Andronova and M. E. Schlesinger, "Causes of Temperature Changes during the 19th and 20th Centuries," Geophysical Research Letters, Vol. 27, No. 14, 2000, pp. 2137-2140. doi:10.1029/2000GL006109

[9] M. E. Schlesinger, N. G. Andronova, B. Entwistle, A. Ghanem, N. Ramankutty, W. Wang, and F. Yang, "Modeling and simulation of climate and climate change," In: G. C. Castagnoli and A. Provenzale, Eds., Past and Present Variability of the Solar-Terrestrial System: Measurement, Data Analysis and Theoretical Models. Proceedings of the International School of Physics "Enrico Fermi" CXXXIII, IOS Press, Amsterdam, 1997, pp. 389429.

[10] C. P. Morice, J. J. Kennedy, N. A. Rayner and P. D. Jones, "Quantifying Uncertainties in Global and Regional Temperature Change Using an Ensemble of Observational Estimates: The HadCRUT4 Dataset," Journal of Geophysical Research, Vol. 107, No. D08101, 2012, 22 pp. doi:10.1029/2011JD017187

[11] J. Hansen, R. Ruedy, M. Sato and K. Lo, "Global Surface Temperature Change," Reviews of Geophysics, Vol. 48, No. RG4004, 2010, 29 pp. doi:10.1029/2010RG000345

[12] T. M. Smith, R. W. Reynolds, T. C. Peterson and J. H. Lawrimore, "Improvements to NOAA's Historical Merged Land-Ocean Surface Temperature Analysis," Journal of Climate, Vol. 21, No. 10, 2008, pp. 2283-2296. doi:10.1175/2007JCLI2100.1

[13] K. Ishihara, "Calculation of Global Surface Temperature Anomalies with COBE-SST," (Japanese) Weather Service Bulletin, Vol. 73, 2006, pp. S19-S25. 
[14] K. Ishihara, "Estimation of Standard Errors in Global Average Surface Temperature," (Japanese) Weather Service Bulletin, Vol. 74, 2007, pp. 19-26.

[15] S. Levitus, J. I. Antonov, T. P. Boyer, R. A. Locarnini, H. E. Garcia and A. V. Mishonov, "Global Ocean Heat Content 1955-2008 in Light of Recently Revealed Instrumentation Problems," Geophysical Research Letters, Vol. 36, No. L07608, 2009, 5 pp. doi:10.1029/2008GL037155

[16] R. K. Kaufmann, H. Kauppi, M. L. Mann and J. H. Stock, "Reconciling anthropogenic climate change with observed temperature 1998-2008," Proceedings of the National Academy of Sciences, Vol. 108, No. 29, 2011, pp. 1179011793. doi:10.1073/pnas. 1102467108

[17] C. MacFarling Meure, D. Etheridge, C. Trudlinger, P. Steele, R. Langenfelds, T. van Ommen, A. Smith and J. Elkins, "Law Dome $\mathrm{CO}_{2}, \mathrm{CH}_{4}$ and $\mathrm{N}_{2} \mathrm{O}$ Ice Core Records Extended to 2000 Years BP," Geophysical Research Letters, Vol. 33, No. 14, 2006, Article ID: L14810. doi:10.1029/2006GL026152

[18] R. G. Prinn, et al., "A History of Chemically and Radiatively Important Gases in Air Deduced from ALE/GAGE/ AGAGE," Journal of Geophysical Research, Vol. 105, No. D14, 2000, pp. 17751-17792. doi:10.1029/2000JD900141

[19] S. J. Walker, R. F. Weiss and P. K. Salameh, "Resconstructed Histories of the Annual Mean Atmospheric Model Fractions for the Halocarbons CFC-11, CFC-12, CFC-113, and Carbon Tetrachloride," Journal of Geophysical Research, Vol. 105, No. C6, 2000, pp. 14285-14296. doi:10.1029/1999JC900273

[20] G. Myhre, E. J. Highwood, K. P. Shine and F. Stordal, "New Estimates of Radiative Forcing Due to Well Mixed Greenhouse Gases," Geophysical Research Letters, Vol. 25, No. 14, 1998, pp. 2715-2718. doi:10.1029/98GL01908

[21] D. S. Stevenson, C. E. Johnson, W. J. Collins, R. G. Derwent, K. P. Shine and J. M. Edwards, "Evolution of Tropospheric Ozone Radiative Forcing," Geophysical Research Letters, Vol. 25, No. 20, 1998, pp. 3819-3822. doi:10.1029/1998GL900037

[22] P. Forster, et al., "Changes in Atmospheric Constituents and Radiative Forcing," In: S. Solomon, et al., Eds., Climate Change 2007: The Physical Science Basis. Contribution of Working Group I to the Fourth Assessment of the Intergovernmental Panel on Climate Change, Cambridge University Press, Cambridge, 2007.

[23] S. J. Smith, J. van Aardenne, Z. Klimont, R. Andres, A. C. Volke and S. Delgado Arias, "Anthropogenic Sulfur Dioxide Emissions 1850-2005," Atmospheric Chemistry and Physics, Vol. 11, No. 6, 2011, pp. 1101-1116. doi:10.5194/acp-11-1101-2011

[24] L. D. D. Harvey, et al., "An Introduction to Simple Climate Models Used in the IPCC Second Assessment Report," Intergovernmental Panel on Climate Change, Bracknell, 1997.

[25] N. G. Andronova and M. E. Schlesinger, "Objective Estimation of the Probability Density Function for Climate Sensitivity," Journal of Geophysical Research, Vol. 106,
No. D19, 2001, pp. 22605-22611. doi:10.1029/2000JD000259

[26] T. C. Bond, E. Bhardwaj, R. Dong, R. Jogani, S. Jung, C. Roden, D. G. Streets and N. M. Trautmann, "Historical Emissions of Black and Organic Carbon Aerosol from Energy-Related Combustion, 1850-2000," Global Biogeochemical Cycles, Vol. 21, No. 2, 2007, Article ID: GB2018. doi:10.1029/2006GB002840

[27] S. D. Fernandes, N. M. Trautmann, D. G. Streets, C. A. Roden and T. C. Bind, "Global Biofuel Use, 1850-2000," Global Biogeochemical Cycles, Vol. 21, No. 2, 2007, Article ID: GB2019. doi:10.1029/2006GB002836

[28] A. Ito and J. E. Penner, "Historical Emissions of Carbonaceous Aerosols from Biomass and Fossil Fuel Burning for the Period 1870-2000," Global Biogeochemical Cycles, Vol. 19, No. 2, 2005, Article ID: GB2028. doi:10.1029/2004GB002374

[29] R. A. Betts, P. D. Falloon, K. K. Goldewijk and N. Ramankutty, "Biogeophysical Effects of Land Use on Climate: Model Simulations of Radiative Forcing and Large-Scale Temperature Change," Agricultural and Forest Meteorology, Vol. 142, No. 2-4, 2007, pp. 216-233. doi:10.1016/j.agrformet.2006.08.021

[30] N. G. Andronova, E. Rozanov, F. Yang, M. E. Schlesinger and G. L. Stenchikov, "Radiative Forcing by Volcanic Aerosols from 1850 to 1994," Journal of Geophysical Research, Vol. 104, No. D14, 1999, pp. 16807-16826. doi:10.1029/1999JD900165

[31] J. Lean, G. Rottman, J. Harder and K. Kopp, "SORCE Contributions to New Understanding of Global Change and Solar Variability," Solar Physics, Vol. 230, No. 1, 2005, pp. 27-53. doi:10.1007/s11207-005-1527-2

[32] Y.-M. Wang, J. L. Lean and N. R. Sheeley, "Modeling the Sun's Magnetic Field and Irradiance since 1713," Astrophyical Journal, Vol. 625, No. 1, 2005, pp. 522-538. doi:10.1086/429689

[33] N. Nakicenovic and R. Swart (Eds.), "Emissions Scenarios," Cambridge University Press, Cambridge, 2000.

[34] J. Lean, J. Beer and R. Bradley, "Reconstruction of Solar Irradiance since 1610: Implications for Climate Change," Geophysical Research Letters, Vol. 22, No. 23, 1995, pp. 3195-3198. doi:10.1029/95GL03093

[35] D. V. Hoyt and K. H. Schatten, "A Discussion of Plausible Solar Irradiance Variations, 1700-1992," Journal of Geophysical Research, Vol. 98, No. A11, 1993, pp. 1889518906. doi:10.1029/93JA01944

[36] M. Ghil, M. R. Allen, M. D. Dettinger, K. Ide, D. Kondrashov, M. E. Mann, A. W. Robertson, A. Saunders, Y. Tian, F. Varadi and P. Yiou, "Advanced Spectral Methods for Climatic Time Series," Reviews of Geophysics, Vol. 40, No. 1, 2002, pp. 3-1-3-41 doi:10.1029/2000RG000092

[37] D. Lindner, "Characterization of the Modes of Interannual-to-Centennial Variability in Observed Near-Surface Temperatures," M. S. Thesis, University of Illinois at Urbana-Champaign, Urbana, 2010.

[38] D. Lindner, M. J. Ring, E. F. Cross and M. E. Schlesinger, "Quasi Periodic Oscillations in the Observed Temperature 
Records," In Preparation.

[39] G. C. Hegerl, F. W. Zwiers, P. Braconnot, N. P. Gillett, Y. Luo, J. A. M. Orsini, N. Nicholls, J. E. Penner and P. A. Stott, "Understanding and Attributing Climate Change," In: S. Solomon, et al., Eds., Climate Change 2007: The Physical Science Basis. Contribution of Working Group I to the Fourth Assessment Report of the Intergovernmental Panel on Climate Change, Cambridge University Press, Cambridge and New York, 2007.

[40] G. C. Hegerl, T. J. Crowley, S. K. Baum, K.-Y. Kim and W. T. Hyde, "Detection of Volcanic, Solar and Greenhouse Gas Signals in Paleo-Reconstructions of Northern Hemispheric Temperature," Geophysical Research Letters, Vol. 30, No. 5, 2003, 4 pp. doi:10.1029/2002GL016635

[41] P. Jones, M. New, D. E. Parker, S. Martin and I. G. Rigor, "Surface Air Temperature and Its Changes over the Past 150 Years," Reviews of Geophysics, Vol. 37, No. 2, 1999, pp. 173-200. doi:10.1029/1999RG900002

[42] IPCC, "Climate Change 2007-The Physical Science Basis, Contribution of Working Group I to the Fourth Assessment Report of the IPCC," Cambridge University Press, Cambridge, 2007.

[43] C. E. Forest, P. H. Stone and A. P. Sokolov, "Constraining Climate Model Parameters from Observed 20th Century Changes," Tellus A, Vol. 60, No. 5, 2008, pp. 911920. doi:10.1111/j.1600-0870.2008.00346.x

[44] S. F. B., Tett, G. S. Jones, P. A. Stott, D. C. Hill, J. F. B. Mitchell, M. R. Allen, W. J. Ingram, T. C. Johns, C. E. Johnson, A. Jones, D. L. Roberts, D. M. H. Sexton and M. J. Woodage, "Estimation of Natural and Anthropogenic Contributions to Twentieth Century Temperature Change," Journal of Geophysical Research, Vol. 107, No. 4306, 2002, 24 pp. doi:10.1029/2000JD000028

[45] A. J. Broccoli, K. W. Dixon, T. L. Delworth, T. R. Knutson, R. J. Stouffer and F. Zeng, "Twentieth-Century Temperature and Precipitation Trends in Ensemble Climate Simulations Including Natural and Anthropogenic Forcing," Journal of Geophysical Research, Vol. 108, No. D24, 2003, 13 pp. doi:10.1029/2003JD003812

[46] P. A. Stott, G. S. Jones and J. F. B. Mitchell, "Do Models Underestimate the Solar Contribution to Recent Climate Change?" Journal of Climate, Vol. 16, No. 24, 2003, pp. 4079-4093. doi:10.1175/1520-0442(2003)016<4079:DMUTSC $>2.0 . C$ $\underline{\mathrm{O} ; 2}$

[47] G. A. Meehl, W. M. Washington, C. M. Ammann, J. M. Arblaster, T. M. L. Wigley and C. Tebaldi, "Combinations of Natural and Anthropogenic Forcings in Twenti-
eth-Century Climate," Journal of Climate, Vol. 17, No. 19, 2004, pp. 3721-3727. doi:10.1175/1520-0442(2004)017<3721:CONAAF $>2.0 . C$ $\underline{\mathrm{O} ; 2}$

[48] T. R. Knutson, T. L. Delworth, K. W. Dixon, I. M. Held, J. Lu, V. Ramaswamy, M. D. Scharzkopf, G. Stenchikov and R. J. Stouffer, "Assessment of Twentieth-Century Regional Surface Temperature Trends Using the GFDL CM2 Coupled Models," Journal of Climate, Vol. 19, No. 9, 2006, pp.1624-1651. doi:10.1175/JCLI3709.1

[49] T. M. L. Wigley and S. C. B. Raper, "Natural Variability of the Climate System and Detection of the Greenhouse Effect," Nature, Vol. 344, 1990, pp. 324-327. doi: $10.1038 / 344324 \mathrm{a} 0$

[50] G. North and M. J. Stevens, "Detecting Climate Signals in the Surface Temperature Record," Journal of Climate, Vol. 11, No. 4, 1998, pp. 563-577.

doi: 10.1175/1520-0442(1998)011<0563\%3ADCSITS $>2$. 0.CO\%3B2

[51] L. D. D. Harvey and R. K. Kaufmann, "Simultaneously Constraining Climate Sensitivity and Aerosol Radiative Forcing," Journal of Climate, Vol. 15, No. 20, pp. 2837 2861.

doi:10.1175/1520-0442(2002)015<2837:SCCSAA $>2.0 . C$ $\mathrm{O} ; 2$

[52] H. Shiogama, T. Nagashima, T. Yokohata, S. Crooks and T. Nozawa, "Influence of Volcanic Activity and Changes in Solar Irradiance on Surface Air Temperature Changes in the Early Twentieth Century," Geophysical Research Letters, Vol. 33, No. L09702, 2006, 4 pp. doi:10.1029/2005GL025622

[53] G. C. Hegerl, T. J. Crowley, M. R. Allen, W. T. Hyde, H. N. Pollack, J. Smerdon and E. Zorita, "Detection of Human Influence on a New, Validated 1500-Year Temperature Reconstruction," Journal of Climate, Vol. 20, No. 4, 2007, pp. 650-666. doi:10.1175/JCLI4011.1

[54] United Nations, "Report of the Conference of the Parties on its Sixteenth Session," The United Nations, Cancun, 2010 .

http://unfccc.int/meetings/cancun_nov_2010/meeting/626 6/php/view/reports.php

[55] M. E. Schlesinger, M. J. Ring and E. F. Cross, "A Fair Plan for Safeguarding Earth's Climate," Journal of Environmental Protection, 2012, In Press.

[56] J. D. Sterman and L. B. Sweeney, "Understanding Public Complacency about Climate Change: Adults' Mental Models of Climate Change Violate Conservation of Matter," Climatic Change, Vol. 80, No. 3-4, 2007, pp. 213-238. doi:10.1007/s10584-006-9107-5 